date for the tablets in the earliest part of that phase, Vinča A. Neustupný $(1968,35)$ noted that an 'idol-shaped pendant' illustrated by Vlassa $(1963,489$, fig. 6 , No. 5) resembled the 'anchor ornaments' common in the Early Bronze Age of the Aegean area. He also stated that such clay 'anchors' were very characteristic of the Late Chalcolithic Cotofeni culture of Transylvania, but without citing any parallels to back his claim. It would be interesting to have a full publication and detailed analysis by a competent specialist of the objects found with the Tartaria tablets.

As for $\mathrm{Cr}_{4}$ dates it is necessary to remember that those for the Neolithic and Chalcolithic of the Balkans cannot be weighed effectively as yet against the evidence of archaeological correlations. The archaeological situation is still very fluid, and chronologies for the Balkans some two thousand years or more apart may be constructed without undue violence to the evidence. The Tartaria tablets are only straws in the wind. But excavations still continuing in Thessaly and Macedonia promise to forge much closer archaeological links between the Balkans and the Aegean, which is itself linked, even if tenuously before the Bronze Age, with Mesopotamia and Egypt.

Calibration has by no means proved a panacea for all the anomalies of $\mathrm{CI}_{4}$ dating, and dates calculated by means of calibration for periods where there is no independent check are not necessarily correct. The more that can be done in the way of narrowing the range of archaeological probabilities, whether by new excavations or by assessing the material already available, the better. The archaeological evidence is itself an important part of the scientific data that must be considered in connexion with $\mathrm{Cr}_{4}$ dating. It is only by checking the $\mathrm{Cr}_{4}$ results against the archaeological probabilities that any lurking imperfections in the method can be brought to light and eventually, no doubt, eliminated.
v. MILoJčıć. I965. Die Tontafeln von Tărtariǎ (Siegenbürgen) und die absolute Chronologie des mitteleuropäischen Neolithikums, Ger- mania, XLIII, 26r-73.

\title{
The First International Congress of Thracology
}

This conference was held in Sofia in July 1972 under the Chairmanship of Professor V. Georgiev. It was a gathering which included Russian, Greek, Turkish, American and western European scholars, as well as many from the Balkan countries and eastern Europe. The subject for discussion was all aspects of Thracian culture. The Congress was formally divided into three parts: history, language, and art and archaeology; the last was the most comprehensive, both in the quantity of the papers, and in the amount of interest and discussion generated.

Among the large amount of material presented was a newly discovered treasure, which included a large gold bowl of the Hallstatt period, from excavations in Sofia; several new Bronze and Iron Age sites were discussed, and some of the most stimulating argument developed around the relationship between local 'knobbed ware' and Troy VII b.2. Some excellent films were shown of Thracian (sensu strictu) mounds and treasures. An exhibition was mounted, for the occasion, of material from museums throughout the country, which ranged from early Neolithic figurines to $3^{\text {rd- }}$ century AD bronze statuettes, but which concentrated mainly on the Ist millennium BC. Highlights included replicas of the Panegurište and Valcitran treasures, the new Sofia treasure, the bronze greave from Vraca (c. 4th-century $\mathrm{BC}$ ), $4^{\text {th-century harness-trappings of silver from }}$ Lukovic and Letnica, and of gold from Mezek, and a gold La Tène torc from Tchibar ( $c$. $300 \mathrm{BC}$ ) together with casting moulds from an unpublished hoard near Razgrad.

After the conference was formally concluded a two-day expedition was organized to visit sites and museums. All praise must go to the extreme generosity and efficiency of our Bulgarian hosts who provided transport and two nights' accommodation free of charge. The expedition 


\section{ANTIQUITY}

covered a great deal of ground in a short time. At Saranci (the prehistoric depôt of the Sofia Archaeological Museum outside Sofia), there was an exhibition of pottery from Karanovo, and the unpublished material from Chavdar, and at Kazanlak Museum a well-arranged display of unpublished material from Kazanlak Tell. The party was shown the excavated Neolithic settlement at Stara Zagora and the excavations in progress in the Roman town of Augusta Traiana; and the first day ended at Malka Vereia, the depôt of the Stara Zagora Archaeological Museum, with the material from Tell Asmak, and Mme Cičikova's excavation at Pšeničevo. On the second day a visit to the tell site at Karanovo was followed by one to the excavations at the Bronze Age tell at Nova Zagora which begins in date where Ezero ends. Pottery was on show for the occasion from Ezero and the Nova Zagora settlement. Finally the expedition went to Plovdiv for a quick visit to the Hellenistic and Roman citadel before ending up at the Archaeological Museum.

It was perhaps a pity that the preliminary information did not make it sufficiently clear that 'Thracian' was to extend back to the earliest Neolithic sites in Bulgaria; as a result, both the conference itself and the excursion were to some extent outside the spheres of interest of the many participants concerned with later periods. However, for the early prehistorians the conference was of considerable value and the Bulgarian organizers must be congratulated on their success. It was agreed that the next congress should take place in Romania in 1977.

JOSEPHINE HOLMES

Miss N. K. Sandars writes:

Although more specialized, and limited in scope, this year's Sofia Congress of Thracology suffered from some of the same difficulties and disabilities as those to which Dr Alexander drew attention in ANTIQUITY for September 1972, writing about the International Congress of Prehistoric and Protohistoric Sciences in Belgrade the year before. The numbers, though less, were still too great for convenience. The list of some 360 participants, given to everyone on arrival, bore little relationship to those actually present. Some allowance must always be made for unavoidable alterations at the last minute, but the proportion here was intolerably high, and had the same effect on the programme of papers as at Belgrade, according to Dr Alexander's account. Regrettably persons from this country were not innocent in this respect. The large number of papers to be accommodated had caused an embarrassed executive to cut down the time allotted to each very sharply, and these allotted times were too often ignored. The need should perhaps be considered for supporting presidents of sections in taking a much stricter line, although in international gatherings, where feelings are sensitive, this is not always easy. Also the proper use and purpose of circulated summaries of papers to be given requires some thought; are they simply summaries to be expanded in full session, or rather a means of by-passing some exposition and providing a point of departure for discussion? In the event the time for discussion was generally inadequate though here the smaller linguistic section may have been more successful.

These thoughts arise from congresses and conferences in general and are not a criticism of the arrangements at Sofia, which was a very enjoyable occasion thanks to the hard work and generous hospitality of our Bulgarian hosts. 

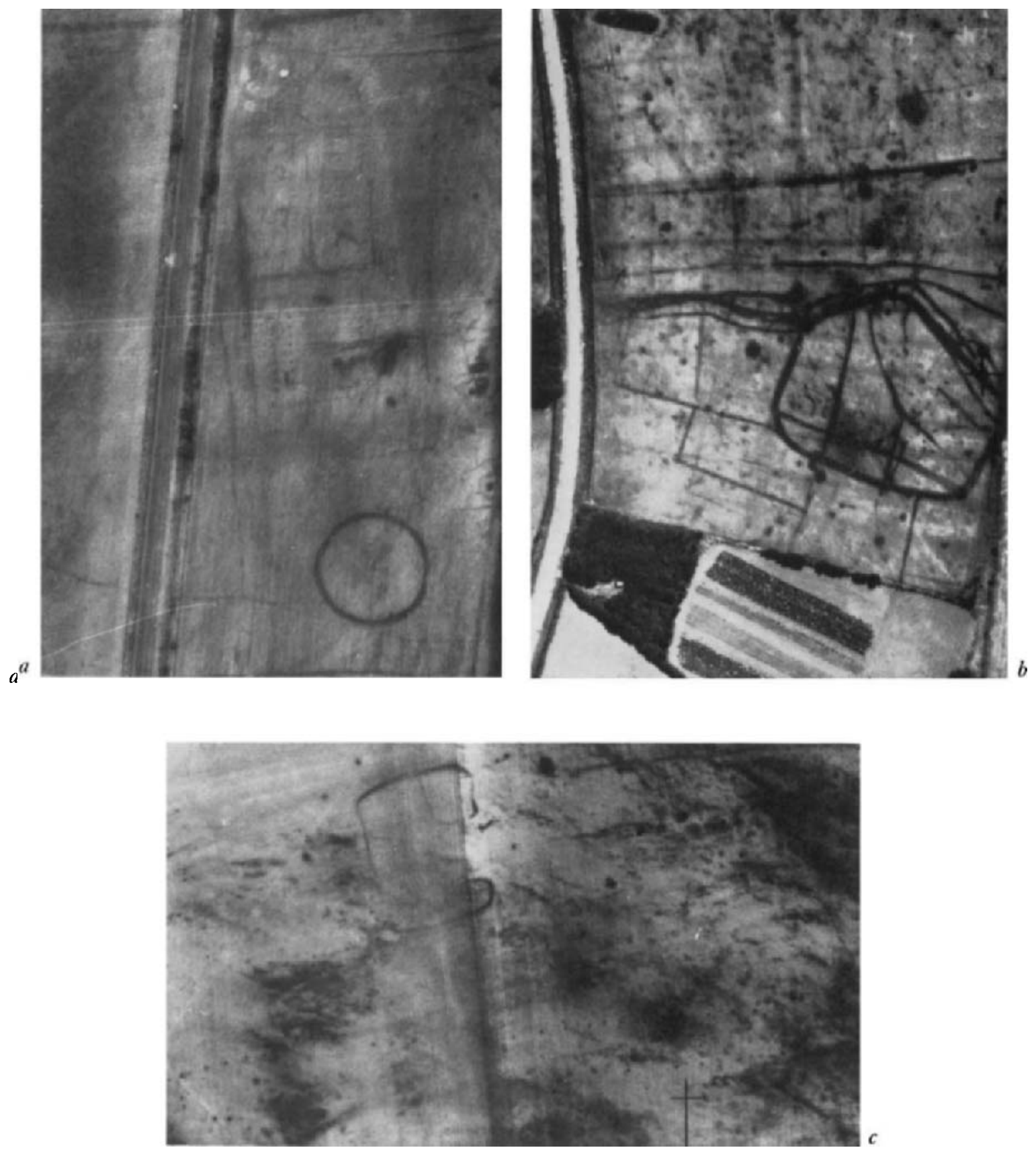

PLATE XV: AIR RECONNAISSANCE, RECENT RESULTS, 30

(a) Cropmarks (TF 08I066) I.5km. Nof Barnack, Northants., 2I.6.1970; (b) crop marks (TF095II4) $0.5 \mathrm{~km}$. NE of Barholm, Lincs., 22.6.1960; (c) crop marks TF (og9066) 0.5 km. $N$ of Bainton, Northants., I1.7.1962. Vertical photographs: scale $1: 2,500$ 


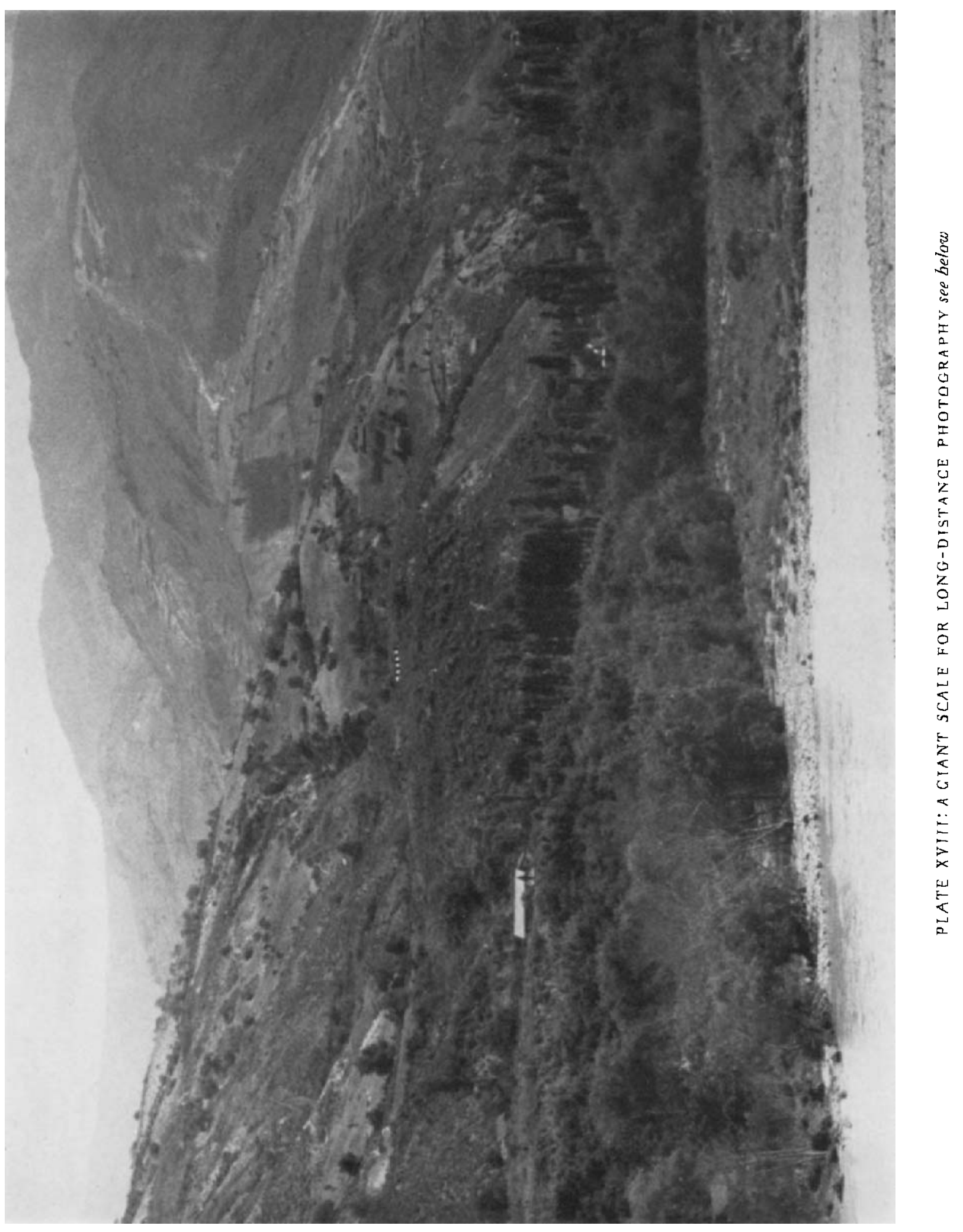



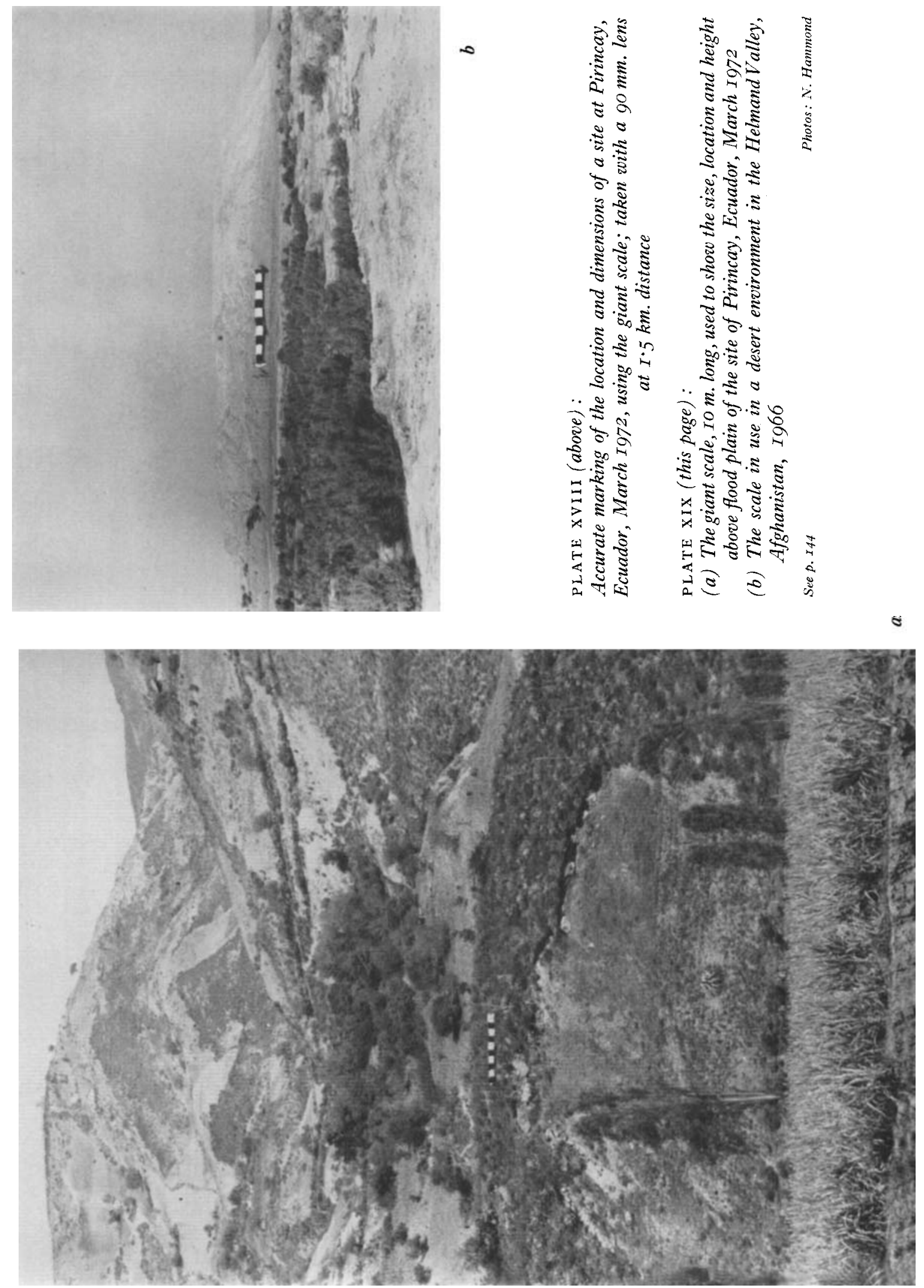